\title{
PENGUJIAN TANAH EKSPANSIF DENGAN SKALA MODEL MENGGUNAKAN KAYU DOWEL SEBAGAI PENGGANTI DINDING PENAHAN TANAH
}

\author{
Richard Samuel $^{1}$ dan Alfred Jonathan Susilo ${ }^{2}$ \\ ${ }^{1}$ Program Studi Sarjana Teknik Sipil, Universitas Tarumanagara, Jl. Letjen S. Parman No.1 Jakarta \\ richardsamueliu14@gmail.com \\ ${ }^{2}$ Program Studi Sarjana Teknik Sipil, Universitas Tarumanagara, J1. Letjen S. Parman No.1 Jakarta \\ alfred@ft.untar.ac.id
}

\begin{abstract}
Foundation is one of the most important thing in a construction. The frequently used foundation in construction is pile foundation. In Indonesia the used of pile is adapt by the condition and quality of the soil. Indonesia had many types of soil, and one of them is expansive soil. Expansive soil is a type of clay that had a swelling and shrinkage potential where the swelling happen when the water content is increase and shrink when the water content decreased. One of the mineral that can cause swelling is montmorillonite mineral in expansive soil. The chemical chain between particles that influenced by the increase of water content is causing montmorillonite mineral to swell. The focus of this research is lateral movement that happened to pile as an effect of the swelling properties in expansive soil. This analysis will also inform the effectiveness on using different size and number of pile in expansive soil.
\end{abstract}

Keywords: expansive soil; montmorillonite; swelling; shrinkage; water content

\begin{abstract}
ABSTRAK
Fondasi merupakan salah satu bagian terpenting dalam suatu konstruksi. Salah satunya yang sering digunakan pada proses pelaksanaan konstruksi adalah fondasi tiang pancang. Di Indonesia sendiri penggunaan fondasi tiang pancang disesuaikan dengan kondisi dan kualitas dari tanah yang ada. Indonesia memiliki berbagai macam tipe dan jenis tanah yang berbeda, salah satunya adalah tanah ekspansif. Tanah ekspansif merupakan jenis lempung yang memiliki daya pengembangan dan penyusutan dimana pengembangan tersebut terjadi jika adanya penambahan kadar air dan menyusut ketika terjadi pengurangan kadar air. Salah satu yang dapat menjadi penyebab terjadinya pengembangan adalah kandungan mineral montmorillonite yang terdapat pada tanah ekspansif. Ikatan kimia antar partikel yang dipengaruhi oleh adanya peningkatan kadar air tanah menyebabkan mineral montmorillonite pada tanah ekspansif tersebut akan mengembang. Analisis yang dilakukan akan berfokus pada pergeseran lateral yang terjadi pada tiang pancang sebagai akibat dari dampak pengembangan yang terjadi pada tanah ekspansif. Analisis ini juga menghasilkan efektivitas pada penggunaan ukuran dan jumlah tiang pancang ditanah ekspansif.
\end{abstract}

Kata kunci: tanah ekspansif; montmorillonite; pengembangan; penyusutan; kadar air

\section{PENDAhULUAN}

Pada pelaksanaan konstruksi, tanah merupakan salah satu bagian terpenting yang merupakan tempat atau dasar bagi suatu bangunan untuk dapat berdiri di atasnya. Tanah merupakan gumpalan mineral yang tidak terkonsolidasi (lepas) dengan atau tanpa bahan organik yang ditemukan di permukaan kerak bumi (Shah, Mengal, \& Mandokhail, 2017). Pengujian untuk mengetahui kondisi tanah sangat perlu dilakukan sebelum proses pelaksanaan konstruksi dijalankan karena kondisi tanah sangat berpengaruh terhadap bangunan yang berada di atasnya.

Indonesia merupakan negara beriklim tropis yang memiliki tanah ekspansif, dimana hal tersebut merupakan suatu masalah yang harus diatasi (Gobena \& Suppiah, 2019). Tanah ekspansif merupakan tipe tanah yang volumenya dapat berubah dikarenakan sangat bergantung pada kadar airnya (Khademi \& Budiman, 2016). Perubahan musim dapat menyebabkan perubahan volume pada tanah ekspansif, yang dapat merusak struktur yang dibangun di atasnya. Evaluasi potensi pembengkakan dan tekanan pembekakan sangat penting dalam mendesain pondasi. (Rao, Phanikumar, \& Sharma, 2004) 
Pada penelitian yang dilakukan ini diperlukan adanya batasan agar fokus permasalahan dan tujuan penelititan tetap tercapai. Adapun batasan-batasan masalah pada penelitian ini adalah sebagai berikut:

1. Pergeseran lateral yang terjadi hanya dicoba pada tiang jenis bulat (spun pile).

2. Sampel tanah yang digunakan adalah tanah ekspansif.

3. Tidak menganalisis penyusutan pada tanah ekspansif.

4. Tidak memperhitungkan penurunan tanah.

Rumusan masalah yang akan dibahas pada penelitian ini adalah efektifitas penggunaan jumlah dan ukuran tiang pancang guna mengatasi dampak dari pengembangan yang terjadi pada tanah ekspansif serta pergeseran lateral yang terjadi akibat beban diatas tanah ekspansif.

Adapun beberapa tujuan yang ingin dicapai dalam penelitian ini adalah:

1. Untuk mengetahui seberapa besar pergeseran lateral yang terjadi pada tiang pancang sebelum dan sesudah terjadinya pengembangan pada tanah ekspansif.

2. Untuk mengetahui efektifitas penggunaan ukuran serta panjang tiang pancang dalam mengatasi dampak dari tanah ekspansif.

\section{Tanah ekspansif}

Tanah ekspansif merupakan jenis lempung yang memiliki daya pengembangan dan penyusutan yang sangat besar dimana pengembangan tersebut terjadi jika adanya penambahan kadar air dan menyusut ketika terjadi pengurangan kadar air. Adapun potensi pengembangan lainnya disebabkan oleh adanya perubahan kelembaban di dalam tanah. Tanah ekspansif mengandung sifat mineral ekspansif dengan kapasitas pertukaran ion yang tinggi, sehingga menghasilkan pengembangan dan penyusutan yang tinggi jika ada perubahan kadar air (Sudjianto, Cakrawala, \& Aditya, 2012). Pada umumnya, tanah ekspansif banyak mengandung mineral montmorillonite yang memiliki kemampuan menyusut dan mengembang yang sangat besar. Pada saat mineral tersebut menyerap air dengan volume yang besar, maka semakin bertambah pula volume tanah yang dapat mempengaruhi kekuatan struktur bangunan yang menempati tanah tersebut. Ketika tanah tersebut mengembang, dapat menyebabkan seperti rusaknya pelat lantai bangunan dan ketika tanah tersebut menyusut, kekuatan dari pondasi dapat terganggu atau bahkan merusak pondasi dikarenakan penyusutan tersebut menyebabkan munculnya rongga sehingga sisi pondasi tidak langsung menempel pada tanah. Perubahan volume pada tanah ekspansif pada dasarnya dihindari karena alasan stabilitas, dimana pengembangan tanah tersebut dipengaruhi oleh rasio kekosongan dan kadar air (Nagaraj, Munnas, \& Sridharan, 2010).

Tanah ekspansif mengandung mineral-mineral yang memiliki kemampuan untuk mengembang. Mineral tersebut antara lain:

\section{a.Montmorillonite}

Montmorillonite merupakan jenis mineral yang memiliki sifat ekspansif yang tinggi. Mineral ini tersusun atas satu lembar aluminium oktahedra dan dua lembar silika tetrahedra. Dua lembar silika tetrahedra tersebut diikat oleh ikatan Van der Waals yang lemah sehingga dengan mudah air dapat masuk dan memisahkan lapisannya. Hal tersebut menyebabkan mineral montmorillonite dapat mengembang dengan mudah pada saat adanya tambahan kadar air. Seperti yang telah dijelaskan, berikut bentuk gambaran skema dari mineral montmorillonite yang dapat dilihat pada gambar 1 . 

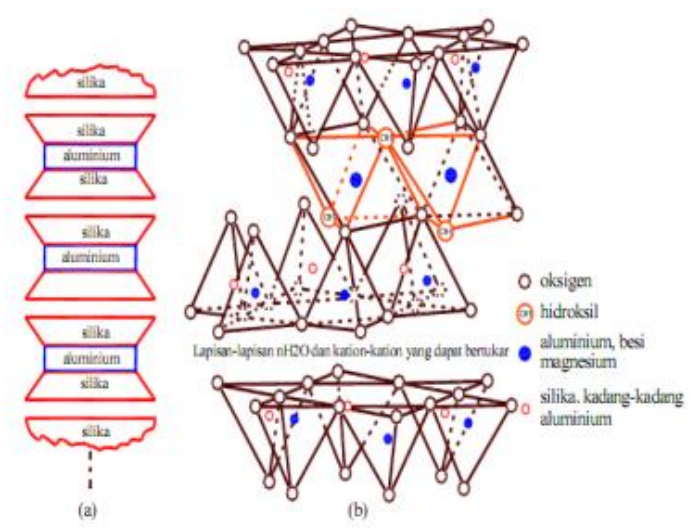

Gambar 1. (a)Diagram skematik struktur montmorrilonite (Lambe, 1953)

(b)Struktur atom montmorrilonite (Grim, 1959)

\section{b.Illite}

Illite tersusun atas mineral yang memiliki sifat yang sulit atau sedikit mengembang jika adanya air yang masuk diantara lembaran-lembarannya. Hal ini dikarenakan lembaran yang tersusun didalamnya yang berupa satu lembar aluminium oktahedra dan dua lembar silika tetrahedra terikat secara bersamaan oleh ikatan lemah ion kalium. Ikatan lemah ion kalium memiliki kekuatan yang lebih kuat dari ikatan ion yang membentuk mineral montmorillonite. Seperti yang telah dijelaskan, berikut bentuk gambaran skema dari mineral illite yang dapat dilihat pada gambar 2 .

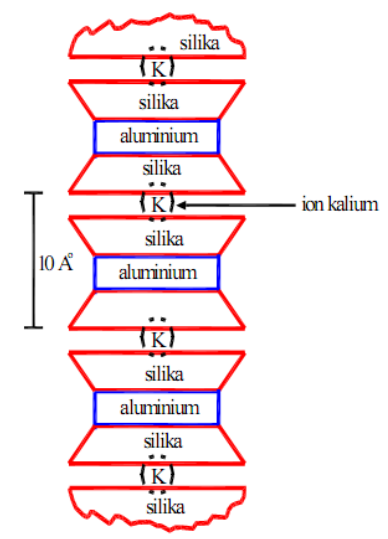

Gambar 2. Diagram skematik struktur illite ( Lambe, 1953)

\section{c.Kaolinite}

Kaolinite merupakan mineral yang tersusun atas satu lembar aluminium oktahedra dan satu lembar silika tetrahedra yang saling terikat secara bersamaan membentuk satu lapisan tunggal. Lembaran silika dan alumunium tersebut diikat oleh ikatan hidrogen sehingga menyebabkan menyebabkan kaolinite tidak memiliki sifat ekspansif. Seperti yang telah dijelaskan, berikut bentuk gambaran skema dari mineral kaolinite yang dapat dilihat pada gambar 3. 


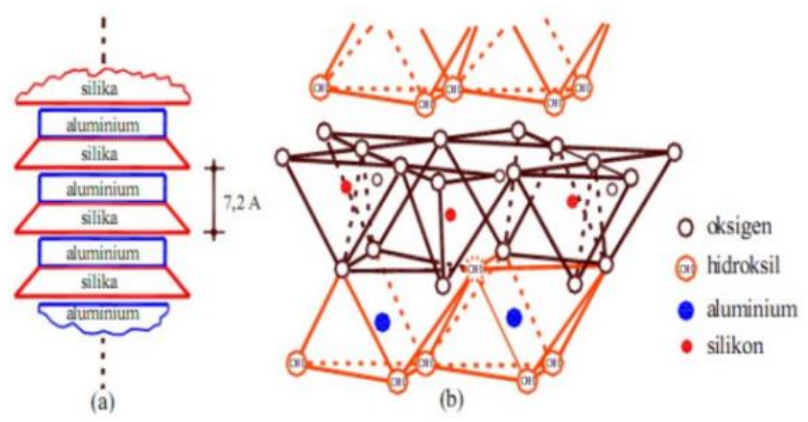

Gambar 3. (a)Diagram skematik struktur kaolinite (Lambe, 1953)

(b)Struktur atom kaolinite (Grim, 1959)

\section{Metode perbaikan tanah ekspansif}

Konstruksi pada tanah ekspansif merupakan tantangan dikarenakan dapat menyebabkan beberapa masalah ((Sandra L. Houston, 2011). Perubahan musim yang terjadi berpengaruh terhadap variasi dari kadar air tanah. Pada tanah ekspansif, kondisi ini mempengaruhi keadaan zona aktif tanah dimana perubahan variasi kadar air tersebut berdampak pada daya rekat tiang fondasi (Tjandra, Indarto, \& Soemitro, 2013).

Hal ini dapat menimbulkan kerusakan yang cukup berpengaruh pada struktur bangunan yang menduduki tanah tersebut. Tanah ekspansif juga akan memberikan tekanan pada permukaan vertikal fondasi, basement, atau dinding penahan yang menghasilkan pergerakan lateral (Das dan Roy, 2014). Kerusakan yang terjadi dapat diatasi dengan menggunakan beberapa metode seperti berikut ini:

\section{Replacement}

Pada umumnya metode yang sering digunakan untuk mengatasi masalah tanah ekspansif adalah dengan mengganti tanah tersebut dengan tanah yang tidak memiliki sifat ekspansif. Metode ini sangat efektif bila dilakukan dengan tapat. Namun harus berhati-hati dalam penggunaan tanah dengan permeabilitas tinggi dikarenakan dapat menyebabkan air masuk kedalam tanah alami sehingga kedalaman zona aktif meningkat.

\section{Lime Treatment}

Salah satu cara yang dilakukan guna mengatasi tanah ekspansif adalah dengan melakukan pencampuran untuk meningkatkan kualitas dari tanah tersebut. Dalam upaya meningkatkan kualitas tanah ekspansif, beberapa pengujian yang dilakukan dengan pencampuran menghasilkan peningkatan dua hingga empat kali daru kualitas tanah sebelumnya (A.seco, F.Ramirez, L.Miqueleiz, dan B.Garcia, 2011)

\section{Prewetting}

Metode ini juga sering disebut presoaking, ponding, dan presaturation, yang dilakukan dengan cara membasahi lokasi dengan air sebelum pekerjaan konstruksi dilakukan dengan upaya untuk meningkatkan kelembaban tanah.

\section{METODE PENELITIAN}

\section{Jenis dan prosedur penelitian}

Penelitian yang digunakan pada skripsi ini adalah analisis mengenai pergeseran lateral yang terjadi serta penggunaan bahan pengganti tiang pancang dalam mengatasi pengembangan pada tanah ekspansif. Penelitian ini dilakukan dengan cara membuat model dari lahan, beban, dan tiang pancang yang sudah dikonversi. Kemudian penentuan ukuran dan jumlah tiang pancang serta pembebanan di atas tanah ekspansif. Setelah itu menganalisis pergeseran lateral yang terjadi pada tiang pancang. Pada penelitian ini, tanah ekspansif yang akan digunakan berlokasi di Sungai Gelam, Jambi dengan kedalaman 0,2 $\mathrm{m}-0,5 \mathrm{~m}$. Bahan lain untuk pembuatan table model diperoleh dari toko material sekitar jakarta dan toko online shop. 


\section{Diagram alir penelitian}

Langkah-langkah penelitian dapat dilihat pada Gambar 4 di bawah:

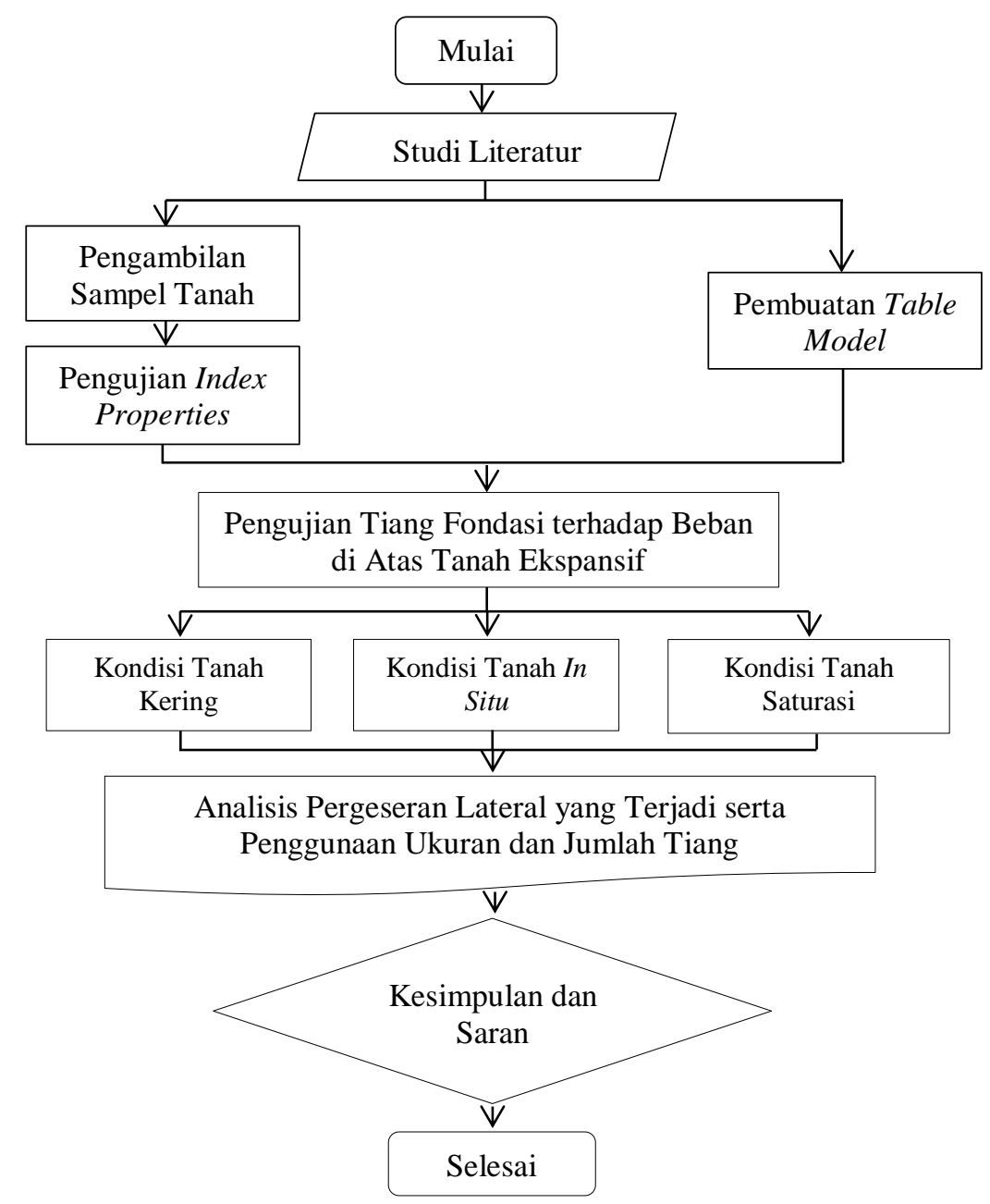

Gambar 4. Bagan alir metodologi penelitian

\section{Pengolahan data}

Studi literatur dilakukan terlebih dahulu untuk mendapatkan referensi karakteristik dari tanah ekspansif sebelum dilakukannya pengolahan data. Setelah studi literatur selesai dilakukan, akan dilanjutkan dengan pengolahan data hasil uji free swell test dan pergeseran lateral yang terjadi pada kayu pengganti dinding penahan tanah. Data tersebut kemudian akan diolah secara manual hua mendapatkan perbandingan hasil perdeseran lateral antar diameter kayu yang digunakan.

\section{HASIL DAN PEMBAHASAN}

\section{Uji penentuan karakteristik tanah ekspansif}

Studi literatur dilakukan untuk mendapatkan referensi dalam menentukan karakteristik tanah ekspansif. Studi literatur dilakukan terhadap beberapa jurnal yang telah meneliti kadar air (water content), specific gravity $\left(\mathrm{G}_{\mathrm{s}}\right)$, batas-batas konsistensi (atterberg limits), dan analisa saringan (grain size analysis) tanah ekspansif. Dari beberapa jurnal yang telah dilakukan studi literatur, dapat dirangkum hasil uji penentuan karakteristik tanah ekspansif pada Tabel 1 di bawah ini. 
Tabel 1. Hasil pengujian tanah ekspansif (Gunarso, 2017)

\begin{tabular}{|c|c|c|c|}
\hline Pengujian & Nilai & Satuan & Notasi \\
\hline \multicolumn{4}{|l|}{ Pengujian Indeks Properties } \\
\hline a. Kadar Air & 34,84 & $\%$ & $\mathrm{w}$ \\
\hline b. Berat Jenis & 2,6568 & $\mathrm{gr} / \mathrm{cm} 3$ & Gs \\
\hline c. Berat Isi & 1,6309 & $\mathrm{gr} / \mathrm{cm} 3$ & \\
\hline d. Liquid Limit & 75,1 & $\%$ & LL \\
\hline e. Plastic Limit & 32,26 & $\%$ & PL \\
\hline f. Plasticity Index & 42,84 & $\%$ & PI \\
\hline g. Shrinkage Limit & 7,64 & $\%$ & SL \\
\hline
\end{tabular}

Analisa Lolos Saringan

$\begin{array}{lcc}\text { a. Saringan No.10 } & 99,8 & \% \\ \text { b. Saringan No.40 } & 98 & \% \\ \text { c. Saringan No.200 } & 96 & \%\end{array}$

Komposisi Ukuran Partikel
a. Pasir

$4 \quad \%$
b. Lanau

43,59 \%
c. Lempung

52,4 \%

Aktivitas

1,01

Swell potential

10,41

$\%$

FSI

Kuat tekan bebas

1,6368

$\mathrm{gr} / \mathrm{cm} 3$

qu

\section{Free swell test}

Pengujian Free swell dilakukan pada sampel tanah yang berlokasi di sekitar Sungai Gelam, Jambi. Pengujian ini dilakukan dengan membuat 3 benda uji yang terdiri dari sampel tanah ekspansif, kemudian diletakkan di dalam wadah yang akan dilihat pengembangannya ketika diberi air dengan kadar air yang ditetapkan.

Pada contoh perhitungan akan digunakan data dari 3 sampel yang telah dikeringkan dan dihaluskan. Untuk hasil dari pengujian free sweel tanah dari 3 sampel yang telah dibuat dapat dilihat pada Tabel 2. Sampel ketika belum dilakukan pengujian pada Gambar 4 dan hasil ketika sampel telah dilakukan pengujian dapat dilihat pada Gambar 5. 
Tabel 2. Hasil pengujian free swell tanah ekspansif sungai gelam, jambi

\begin{tabular}{|c|c|c|c|}
\hline $\begin{array}{l}\text { Sampel } \\
\text { Tanah }\end{array}$ & Sampel A & Sampel B & Sampel C \\
\hline $\begin{array}{l}\text { hs, tinggi } \\
\text { tanah } \\
\text { sebelum } \\
\text { mengembang } \\
(\mathrm{cm})\end{array}$ & 1,4 & 1,3 & 1,3 \\
\hline $\begin{array}{l}\mathrm{h}_{\mathrm{f}}, \text { tinggi } \\
\text { tanah setelah } \\
\text { mengembang } \\
\quad(\mathrm{cm})\end{array}$ & 1,6 & 1,5 & 1,6 \\
\hline FSI (\%) & 14,2857 & 15,3847 & 23,0769 \\
\hline
\end{tabular}

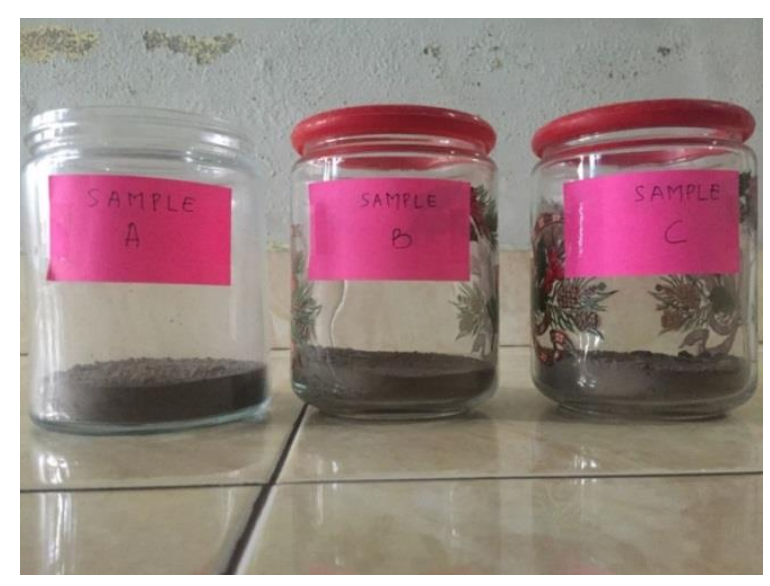

Gambar 5. Sampel Tanah Ekspansif Sungai Gelam, Jambi

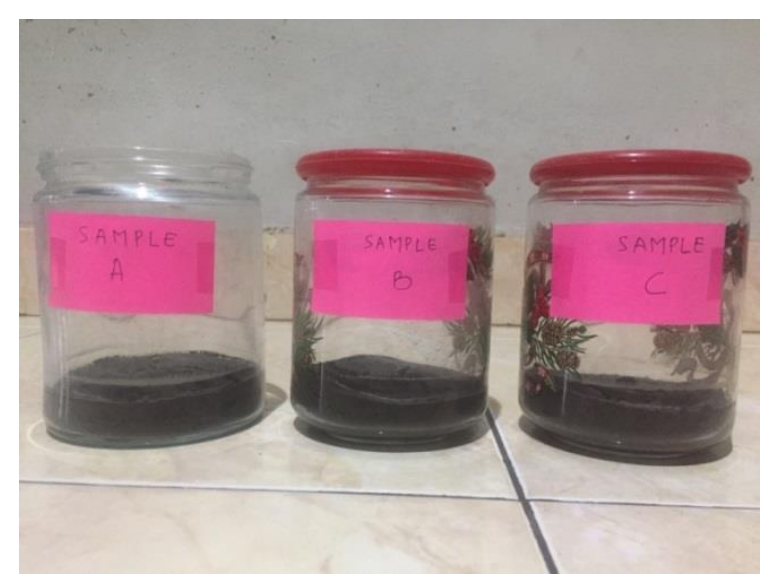

Gambar 6. Sampel tanah ekspansif sungai gelam, Jambi setelah pengujian free swell

\section{Uji pergeseran lateral}

Pengujian pergeseran lateral ini dilakukan pada sampel tanah yang berlokasi di sekitar Sungai Gelam, Jambi. Pengujian ini dilakukan dengan membuat table model berdasarkan skala perbandingan 1:20 terhadap skala aslinya dengan menggunakan container box yang diisi sampel pasir. Untuk data teknis penelitian dapat dilihat pada Tabel 
3 dan Tabel 4. Untuk data hasil pengujian pergeseran lateral dapat dilihat pada Tabel 5. Contoh gambar/foto hasil dari pengujian pergeseran lateral dapat dilihat pada Gambar 6 hingga Gambar 10.

Tabel 3. Data teknis pengujian pergeseran lateral (skala asli)

\begin{tabular}{cccc}
\hline & Diameter $400 \mathrm{~mm}$ & Diameter $500 \mathrm{~mm}$ & Diameter $600 \mathrm{~mm}$ \\
\hline Berat beban $(\mathrm{kg})$ & 100 & 100 & 100 \\
$\begin{array}{c}\text { Luas permukaan beban } \\
\left(\mathrm{m}^{2}\right)\end{array}$ & 5,6 & 4,8 & 4,8 \\
$\begin{array}{c}\text { Jarak beban tehadap } \\
\text { dinding penahan }(\mathrm{m})\end{array}$ & 2 & 2 & 2 \\
Jumlah tiang & 5 & 4 & 4 \\
\hline
\end{tabular}

Tabel 4. Data Teknis Pengujian Pergeseran Lateral (Skala 1:20)

\begin{tabular}{cccc}
\hline & Diameter $20 \mathrm{~mm}$ & Diameter $25 \mathrm{~mm}$ & Diameter $30 \mathrm{~mm}$ \\
\hline Berat beban $(\mathrm{kg})$ & 5 & 5 & 5 \\
$\begin{array}{c}\text { Luas permukaan beban } \\
\left(\mathrm{cm}^{2}\right)\end{array}$ & 140 & 120 & 120 \\
$\begin{array}{c}\text { Jarak beban tehadap } \\
\text { dinding penahan }(\mathrm{cm})\end{array}$ & 10 & 10 & 10 \\
Jumlah tiang & 5 & 4 & 4 \\
\hline
\end{tabular}


Tabel 5. Hasil Pengujian Pergeseran Lateral Tanah Ekspansif Sungai Gelam, Jambi

\begin{tabular}{|c|c|c|c|}
\hline & \multicolumn{3}{|c|}{ Hasil pergeseran lateral (mm) } \\
\hline & $\begin{array}{c}\text { Diameter } \\
20 \mathrm{~mm}\end{array}$ & $\begin{array}{l}\text { Diameter } \\
25 \mathrm{~mm}\end{array}$ & $\begin{array}{c}\text { Diameter } \\
30 \mathrm{~mm}\end{array}$ \\
\hline Penambahan beban & - & - & - \\
\hline $\begin{array}{l}\text { Penambahan air } \\
250 \mathrm{ml}\end{array}$ & - & - & - \\
\hline $\begin{array}{c}\text { Penambahan air } \\
125 \mathrm{ml}\end{array}$ & 1 & 1 & - \\
\hline $\begin{array}{l}\text { Penambahan air } \\
250 \mathrm{ml}\end{array}$ & 2 & 2 & 1 \\
\hline $\begin{array}{c}\text { Penambahan air } \\
250 \mathrm{ml}\end{array}$ & $\mathrm{X}$ & $\mathrm{X}$ & 1.5 \\
\hline
\end{tabular}

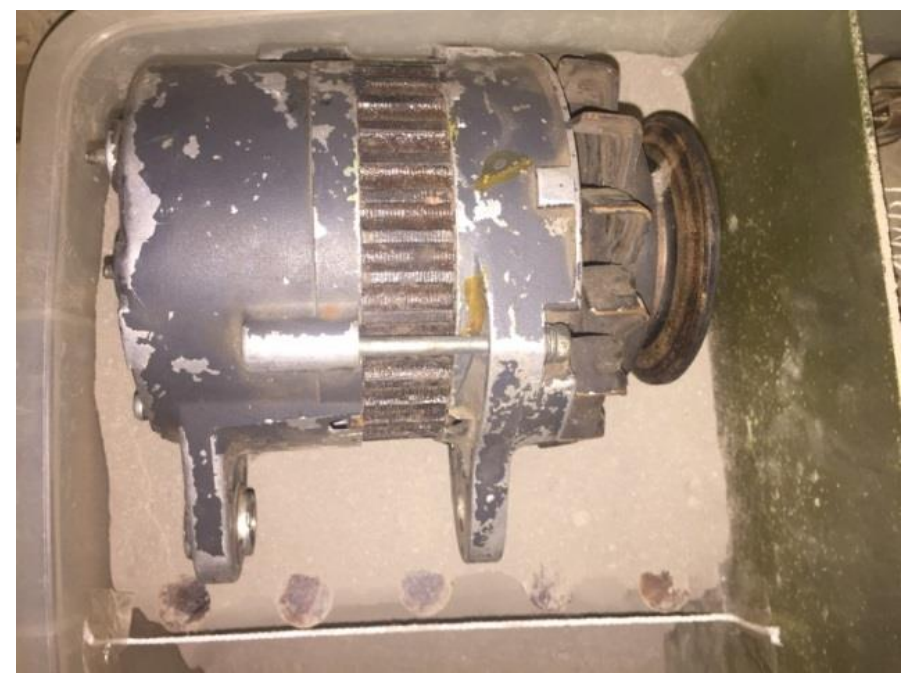

Gambar 7. Perletakan beban di atas lahan dengan tiang penahan diameter 20 


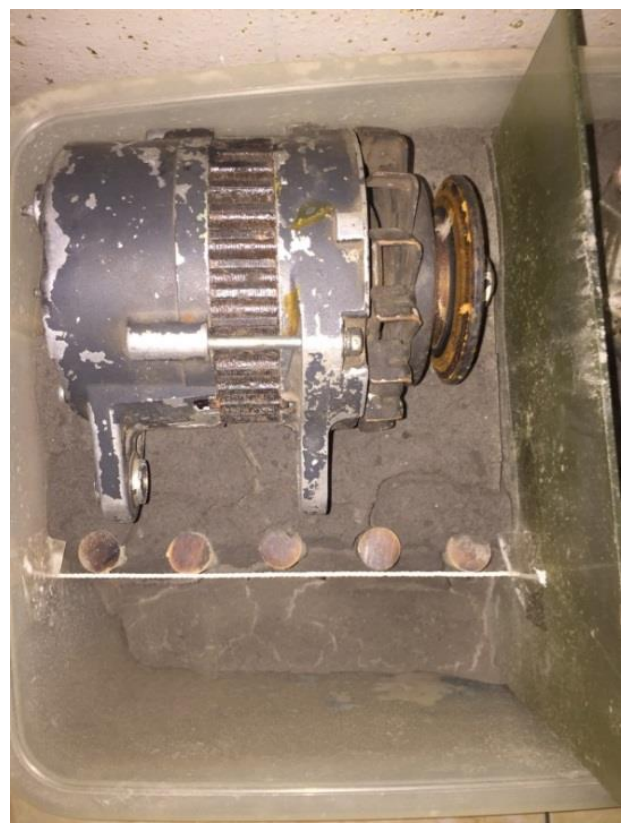

Gambar 8. Tiang penahan diameter 20 setelah penyemprotan $250 \mathrm{ml}$

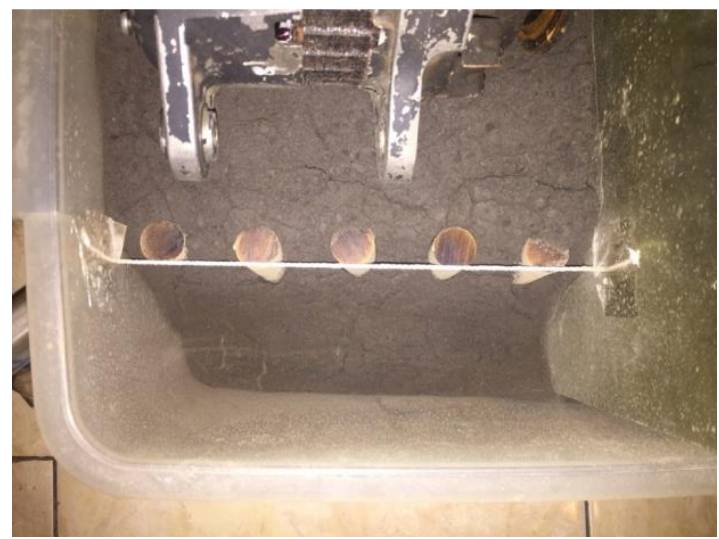

Gambar 9. Tiang penahan diameter 20 setelah penambahan penyemprotan $125 \mathrm{ml}$

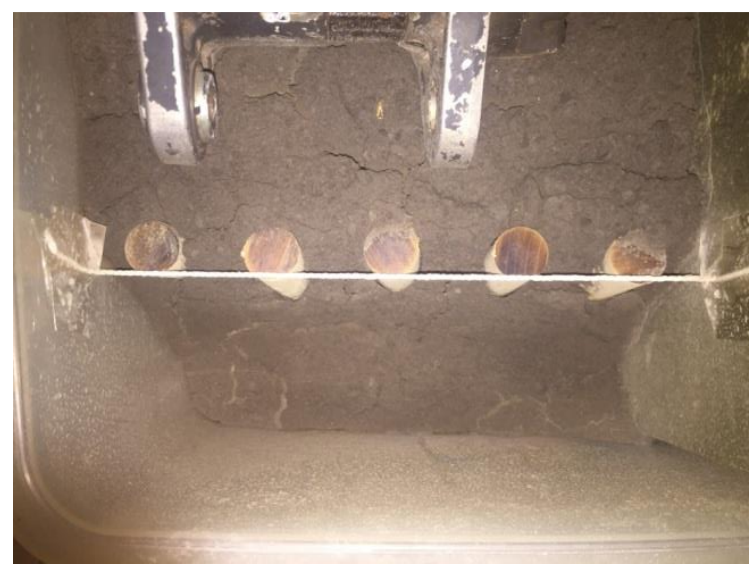

Gambar 10. Tiang penahan diameter 20 setelah penambahan penyemprotan $250 \mathrm{ml}$ 


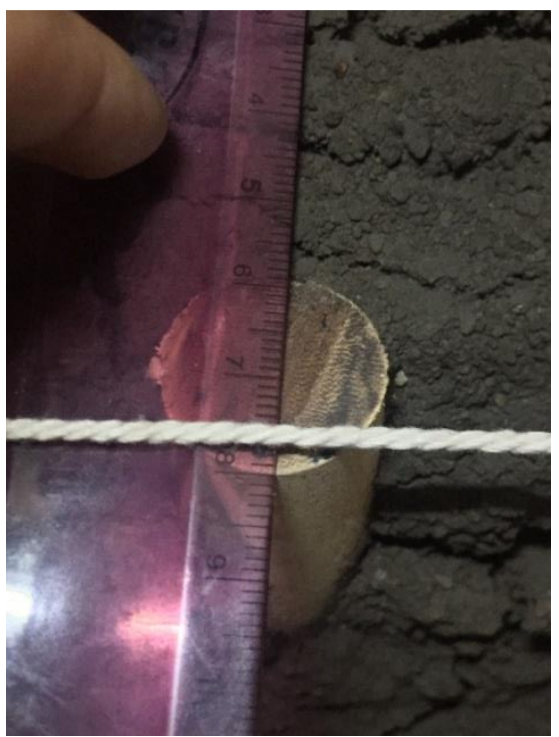

Gambar 11. Hasil pengukuran pergeseran lateral pada tiang penahan diameter 20

\section{KESIMPULAN DAN SARAN}

\section{Kesimpulan}

Berdasarkan analisis yang dilakukan, didapatkan beberapa kesimpulan sebagai berikut:

1. Tiang penahan dengan diameter $400 \mathrm{~mm}(20 \mathrm{~mm})$ dan $500 \mathrm{~mm}(25 \mathrm{~mm})$ dapat menahan beban $100 \mathrm{~kg}(5 \mathrm{~kg})$ ketika terjadinya penambahan air (hujan) sebanyak 13 liter $(650 \mathrm{ml})$.

2. Penambahan air sebanyak 13 liter $(650 \mathrm{ml})$ pada lahan tanah ekspansif dengan tiang penahan berukuran 400 $\mathrm{mm}(20 \mathrm{~mm})$ dan $500 \mathrm{~mm}(25 \mathrm{~mm})$ terjadi pergeseran sejauh $4 \mathrm{~cm}(2 \mathrm{~mm})$.

3. Terjadi kegagalan/keruntuhan tanah pada lereng tiang penahan dengan ukuran $600 \mathrm{~mm}$ (30 mm) pada penambahan air 5 liter $(250 \mathrm{ml})$ pada kadar air sebanyak 13 liter $(650 \mathrm{ml})$.

4. Tiang penahan dengan diameter $400 \mathrm{~mm}(20 \mathrm{~mm})$ dan $500 \mathrm{~mm}(25 \mathrm{~mm})$ tidak mengalami pergeseraan pada penambahan 5 liter $(250 \mathrm{ml})$ air pertama.

5. Dari beberapa hasil di atas, penulis menyimpulkan bahwa tiang penahan dengan diameter $400 \mathrm{~mm}(20 \mathrm{~mm})$ dan $500 \mathrm{~mm}(25 \mathrm{~mm})$ dapat menahan pengembangan yang terjadi pada tanah ekspansif yang diberi beban sebesar $100 \mathrm{~kg}(5 \mathrm{~kg})$ dengan penambahan air sebanyak 13 liter $(650 \mathrm{ml})$ dengan pergerakan lateral sebesar 4 $\mathrm{cm}(2 \mathrm{~mm})$ tanpa terjadinya keruntuhan tanah pada lereng. Sedangkan untuk tiang penahan dengan diameter $600 \mathrm{~mm}(30 \mathrm{~mm})$ hanya dapat menahan pengembangan tanah ekspansif yang diberi beban sebesar $100 \mathrm{~kg}(5$ $\mathrm{kg}$ ) dengan penambahan air sebanyak 7.5 liter $(375 \mathrm{ml})$ air tanpa pergerakan. Setelah penambahan air berikutnya terjadi kegagalan/keruntuhan pada lereng tiang penahan dengan diameter $600 \mathrm{~mm}(30 \mathrm{~mm})$ dengan total penambahan air sebanyan 13 liter ( $650 \mathrm{ml})$.

\section{Saran}

Berdasarkan hasil analisis yang telah dilakukan, adapun saran untuk melengkapi studi ini adalah:

1. Untuk penelitian selanjutnya, diharapkan untuk menggunakan skala perbandingan yang lebih detail agar hasil yang didapatkan lebih akurat.

2. Dari hasil analisis yang telah dilakukan, diharapkan dapat dilakukan analisis terhadap variabel lainnya agar didapatkan hasil yang lebih akurat.

3. Penggunaan tiang pengganti dinding penahan dengan jumlah yang lebih banyak serta diameter kecil lebih disarankan dibandingkan tiang pengganti dinding penahan dengan jumlah yang sedikit dan diameter lebih besar. Berdasarkan penelitian diatas, penggunaan tiang pengganti dinding penahan dengan jumlah yang banyak walaupun diameter kecil dapat meminimalisir terjadinya longsor tanah pada sisi galian.

\section{DAFTAR PUSTAKA}

Sandra L. Houston, Heather B. Dye, Claudia E. Zapata, Kenneth D. Walsh, \& and William N. Houston. "Study of Expansive Soils and Residential Foundations on Expansive Soils in Arizona.” (2011).

A.Seco, et al. Stabilization of expansive soils for use in construction. 2011. 
Das, Arindam dan Sabyasachi Roy. Effect of Expansive Soil on Foundation and Its Remedies. 2014.

Gobena, Jemal Aliy dan S. Suppiah. "Strength Characteristics Of Tropical Expansive Soil." (2019).

Khademi, Faezehossadat dan Jeff Budiman. "Expansive Soils: Cause and Treatments." (2016).

Nagaraj, H., M. Munnas dan A. Sridharan. "Swelling Behavior of Expansive Soils." (2010).

Rao, A.S., B.R. Phanikumar dan R.S. Sharma. Prediction of swelling characteristics of remoulded and compacted expansive soils using free swell index (2004).

Sandra L. Houston, Ph.D., M.ASCE, et al. (2011). "Study of Expansive Soils and Residential Foundations on Expansive Soils in Arizona." (2011).

Shah, Syed Jahanzaib, Ali Nawaz Mengal dan Saeedullah Jan Mandokhail. "Analysis of Swelling Characteristics of Expansive Soil." (2017).

Sudjianto, Agus Tugas, M. Cakrawala dan Candra Aditya. “The Effects of Water Contents.” (2012).

Tjandra, D., Indarto dan R.A.A. Soemitro. The Effects of Water Content Variation on Adhesion Factor of Pile Foundation in Expansive Soil . 2013. 